\title{
The role of peri-implant strains in dental implant systems: a narrative review
}

\author{
Saul Weiner ${ }^{1,2}$, Rafiullah Bashiri ${ }^{3}$, Hongjun Wang ${ }^{1,4}$ \\ ${ }^{1}$ Department of Biomedical Engineering, Stevens Institute of Technology, Hoboken, NJ, USA; ${ }^{2}$ Department of Restorative Dentistry, Rutgers School \\ of Dental Medicine, Newark, NJ, USA; ${ }^{3}$ Department of Prosthodontics, Division of Comprehensive Oral Health, The University of North Carolina, \\ Adams School of Dentistry, Chapel Hill, NC, USA; ${ }^{4}$ Department of Chemistry and Chemical Biology, Stevens Institute of Technology, Hoboken, \\ NJ, USA \\ Contributions: (I) Conception and design: S Weiner, H Wang; (II) Administrative support: None; (III) Provision of study materials or patients: None; \\ (IV) Collection and assembly of data: None; (V) Data analysis and interpretation: None; (VI) Manuscript writing: All authors; (VII) Final approval of \\ manuscript: All authors. \\ Correspondence to: Saul Weiner, DDS. 50 Commerce Street, Newark, NJ 07102, USA. Email: forasaul@aol.com.
}

Objective: The objective of this narrative is to review the significant biomechanical aspects of implant systems, describing the stresses and strains associated with their functional roles in oral rehabilitations.

Background: During the early development of dental implant systems, the integration of the implant within the jawbone was the primary concern of most investigators and clinicians. Currently, with successful integration rates of greater than $90 \%$, the biomechanics of the implant system is receiving more attention. A better understanding of the biomechanics will allow greater simplification and encourage more general practitioners to restore dental implants.

Methods: This narrative systematically describes the role of each component of the oral implant system and its biomechanical relationship with functional oral activities. The most common implant systems include a crown, abutment, implant and connecting screw. Intrinsic and extrinsic jaw movements and tooth contacts during mastication, speech and deglutition subject implant systems to complex forces. In addition, jaw movements during centrally mediated dyskinesias associated with stress, sleep and neurological disorders can also enhance these forces on intraoral implant systems. A number of strategies have been developed seeking mechanical stability of the crown, the raison d'etre of the implant system, including its shape and size as well as its morphology. The abutment, upon which the crown rests, connects the crown with the implant and is stabilized with a screw, which upon tightening, develops a preload at the interface between abutment and the implant to prevent displacement. Finally, the design of the implant, its form, taper and thread pattern that are important for its integration within the jaw bone is also a significant factor for the functional stability of the implant system.

Conclusions: The implant systems available today have been extensively studied and are able to function effectively in the oral cavity.

Keywords: Dental implant; peri-implant strain; bone-implant integration; implant biomechanics; implant abutments

Received: 16 April 2021; Accepted: 21 October 2021; Published online: 09 November 2021.

doi: $10.21037 /$ fomm-21-50

View this article at: https://dx.doi.org/10.21037/fomm-21-50 


\section{Introduction}

One of the phenomena that occur in an oral environment with implants is the presence of strains. It occurs when there are distortions of mechanical structure, resulting from forces acting upon the implant system generated through the skeletal and muscular movement during physiological (such as mastication and speech) and parafunctional activities (such as those associated with central system modulation of the activity of the orofacial musculature during sleep, stress responses and dyskinesias). The structures that are affected by these strains are within or surrounding a dental implant system including the crown, the abutment, the screw and the fixture structures as well as the surrounding osseous structures $(1,2)$ (Figure 1). In view of the clinical relevance of such peri-implant strains, this mini-review concisely discussed the dental implant system, dental implant mechanics, bone-implant integration, bone strain, and peri-implant strain. We present the following article in accordance with the Narrative Review reporting checklist (available at https://fomm.amegroups.com/article/ view/10.21037/fomm-21-50/rc).

\section{Dental implant systems}

Implants are mechanical structures surgically inserted to integrate with the biology of the human body. However an implant system, functionally, serves to replace one or multiple teeth to integrate into the occlusal scheme of the patient (Figure 2). The crown of the implant unit contacts the adjacent teeth. In addition, the implant crown also articulates with the dentition of the opposite jaw. During



Figure 1 Components of a dental implant system in a single unit restoration. function the two opposing dentitions, maxillary and mandibular, contact one another as the contraction of the musculature brings the occlusal surfaces in touch during the jaw closure cycle (3). As shown in Figure 3, both vertical and horizontal forces are present during the closing cycle. The crown height, functioning as a lever arm, influences the strain generated during occlusal closure (4) (Figure 4).

The form of the occlusal surface is also important with regard to the stress applied to the implant system. Its morphology consists of cusps and fossa that interdigitate (Figure 5). During jaw movement, when the dentition of the maxilla and mandible, either natural tooth or implantsupported, contact each other, the implant system readily absorbs the vertical vector with minimal strain. However, the horizontal vector of the cycle introduces stresses that, because of the cuspal angles, can result in strains that make the system unstable and may result in loosening of its components (5).

Strains from occlusal contacts are transferred within the implant system from the crown to the abutment, the screw, to the walls of the implant fixture, and ultimately to the osseous support for the implant system (6) (Figure 6). The strains generated within the abutment are important as they can cause slippage between the abutment and the implant. This in turn can cause looseness of the screw stabilizing the abutment-implant interface. The result may be partial or complete displacement of the crown or alternatively screw fracture. Slippage results from the horizontal forces acting on the occlusal surface of the crown as shown in Figure 7 (7). The nature of the interface between the abutment and the implant has a variety of designs depending upon the implant system (8). Those termed internal connection, either internal or morse cone systems, have the apical end of the abutment projecting into the hollow of the implant to various depths with either a hexed or slip fit projection. In general, the deeper the interface between the abutment and the implant, the more stable the connection and the less strain demonstrated in the system. The external hexed implants have a hex design at the top of the implant which fits into a recess within the abutment (Figure 8). Generally speaking, the internal connection systems are more stable with less displacement of the abutment and the crown, exhibiting less strain (9).

If there is slippage between the abutment and the implant, it is usually accompanied by loosening of the screw that connects the abutment to the implant. When the implant system is assembled, the screw is tightened, the shank of the screw is stretched and a clamping force 

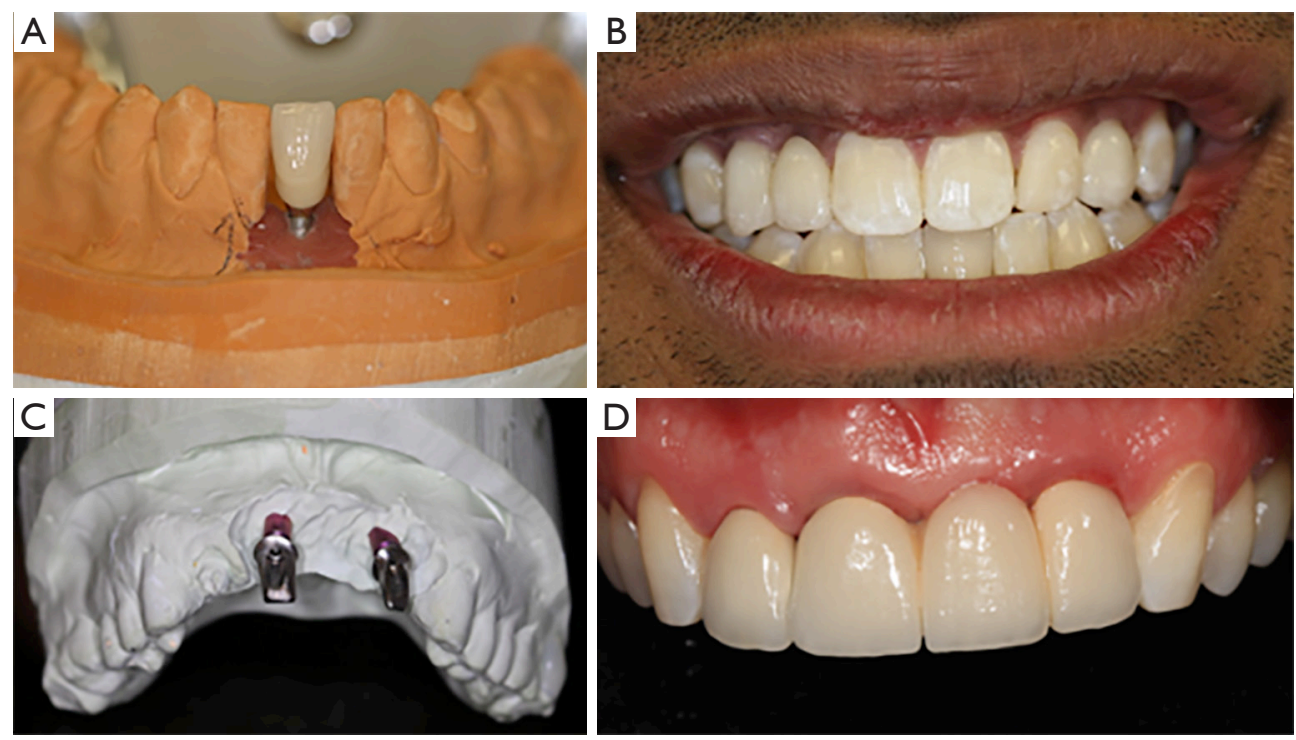

Figure 2 Examples of tooth replacement. (A) Mandibular left central incisor replacement in a cast model. (B) Mandibular central incisor replacement in the oral cavity. (C) Four-unit maxillary replacement in cast model. (D) Four-unit maxillary replacement in oral cavity.

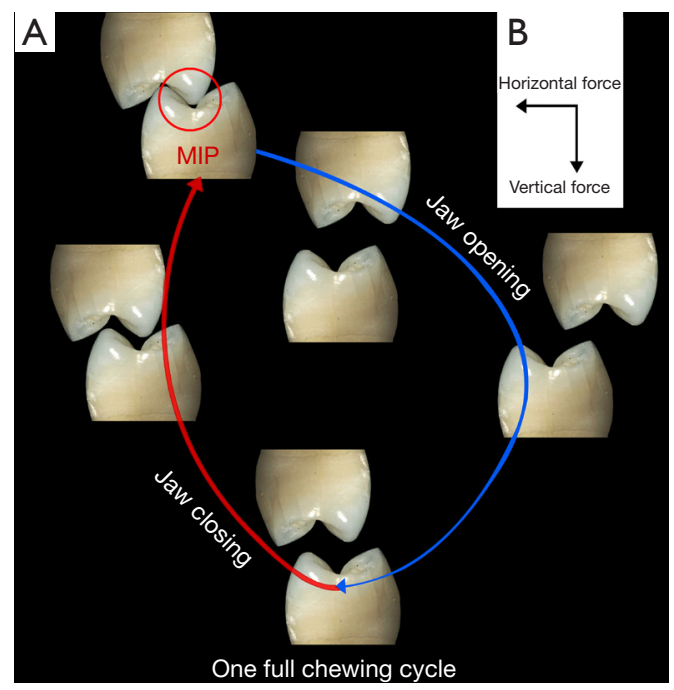

Figure 3 The trajectory of jaw movement during mastication. (A) Diagram of one complete chewing cycle of opening and closing with the teeth contacting in maximum intercuspation (MIP). (B) The horizontal and vertical vectors of the force trajectory during jaw closure.

compresses the abutment into the implant (10) (Figure 9). If the strain from the occlusal forces is greater than the clamping force that holds the abutment to the implant, the screw bends and loosens. As a result, clamping force is lost

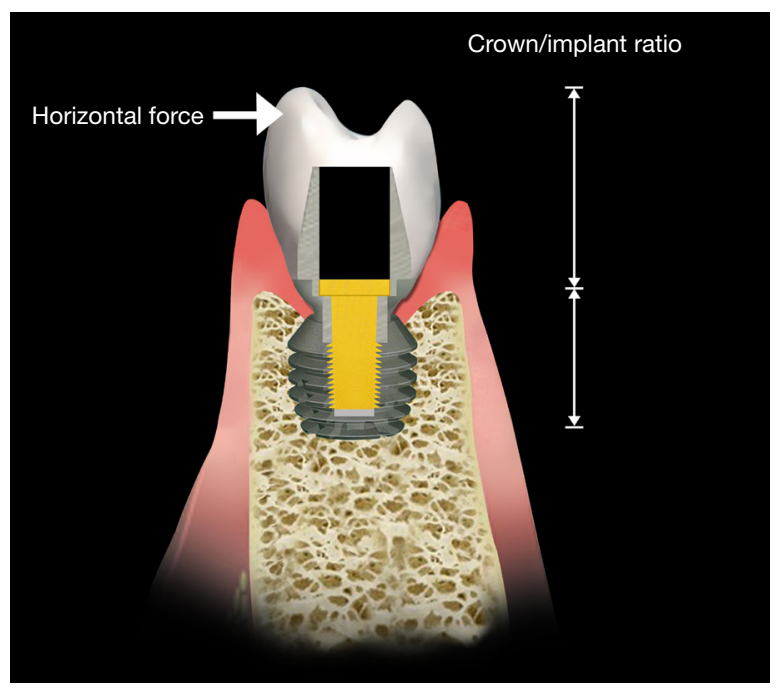

Figure 4 A dental implant system with a large crown-root ratio results in a long lever arm that may exert a torquing force causing screw loosening and damage to the crestal bone.

and the abutment slips away from the implant (10-13).

Dental implants are made from two biocompatible materials, titanium and zirconia. Most dental implants used today are made from titanium (14). More recently, 


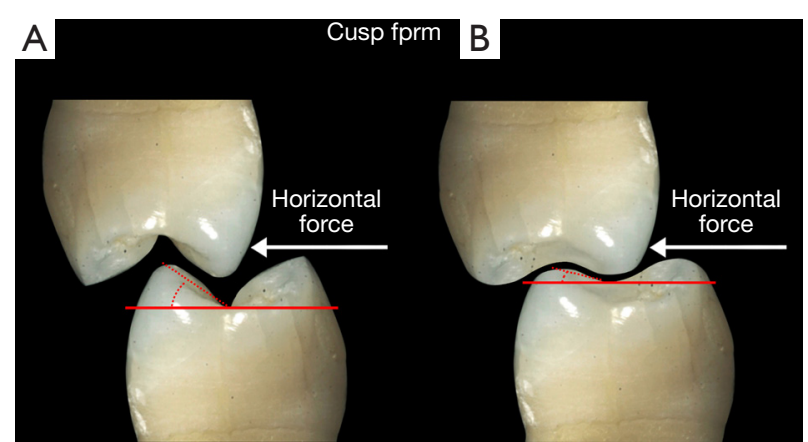

Figure 5 The association between cusp angle and shear force during excursive movements is illustrated. During lateral excursive movements, a crown with steep cuspal angle (A) creates a greater shear force than a crown with smaller cusp angle (B). Larger shear forces can result in occlusal trauma, tooth and implant mobility and implant screw loosening.

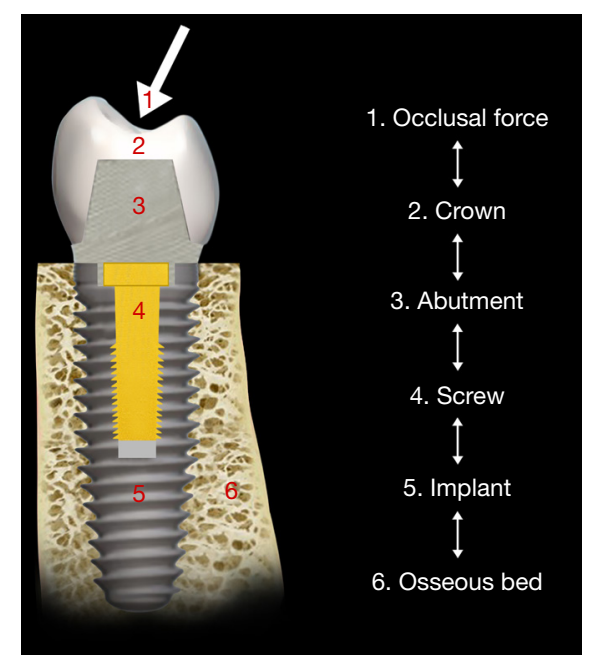

Figure 6 Transmission of forces through the dental implant system is illustrated. Horizontal and vertical forces [1] are transmitted through the crown [2] to the abutment [3] and the screw [4] and then to the dental implant and the osseous bed [5] supporting a dental implant as a complete system.

zirconia implants are also available, but they only represent a very small proportion of currently used implants $(14,15)$. The titanium implants are either made from commercially pure titanium or titanium alloy. The significant difference between them is their respective moduli of elasticity. The titanium alloy material typically composed of titanium, vanadium and aluminum is stiffer than the commercially pure titanium. It has been reported that the bone- implant contact (BIC) is greater for implants made from commercially pure titanium. However, the available evidence shows that the difference is of little or no clinical significance (16). The situation where the modulus of elasticity, and thus the selection of implant must be carefully considered, is an implant insertion in the narrow spaces between other implants or teeth. The narrow diameter implant is more likely to fracture from intraoral shear and lateral stress forces and thus an implant of titanium alloy is preferred (17).

There are several design principles that common to virtually all implant systems available today. The implants have a tapered form and are threaded. A number of thread designs were initially created based mainly upon finite element and photoelastic analyses. However clinical experience has confirmed that the actual design is of less importance provided that two conditions are met (18). Firstly, the threads are self-cutting. Secondly, the diameter of the osteotomy is one half to one mm narrower in diameter than the implant. During insertion of the implant the self-cutting nature of the threads allows the implant to be stabilized within the bone. These implants reduce the strains during insertion since the implant is cutting rather compressing the bone.

The thread design has been shown to be related to the nature of the bone into which the implant is being inserted (19). For softer cancellous bone there is a greater need to stabilize the implant. Accordingly, the pitch and depth of the thread both should be greater to allow the threads of the implant to engage a larger surface area. Cancellous bone is compressible because of the large marrow spaces between trabeculae. The compression process creates denser bone surrounding the implant and improves stability. In the case where the implant is being inserted into cortical bone with dense osteons, the situation is different. The implant thread design has a smaller pitch and shallower threads. As a result of the intrinsic strength of cortical bone, compression is not needed. The implant is more readily stabilized, and the surface area of the bone needed for initial contact is much less. As a matter of fact, rapid tightening of the implant into the cortical bone may lead to a stress pattern that will cause damage and resorption of the bone contacting the implant because of the greater torque force needed to entirely seat the implant (20).

\section{Dental implant mechanics}

Most implant designs today are wider at the region of the interface with the abutment and narrower at the base, the 


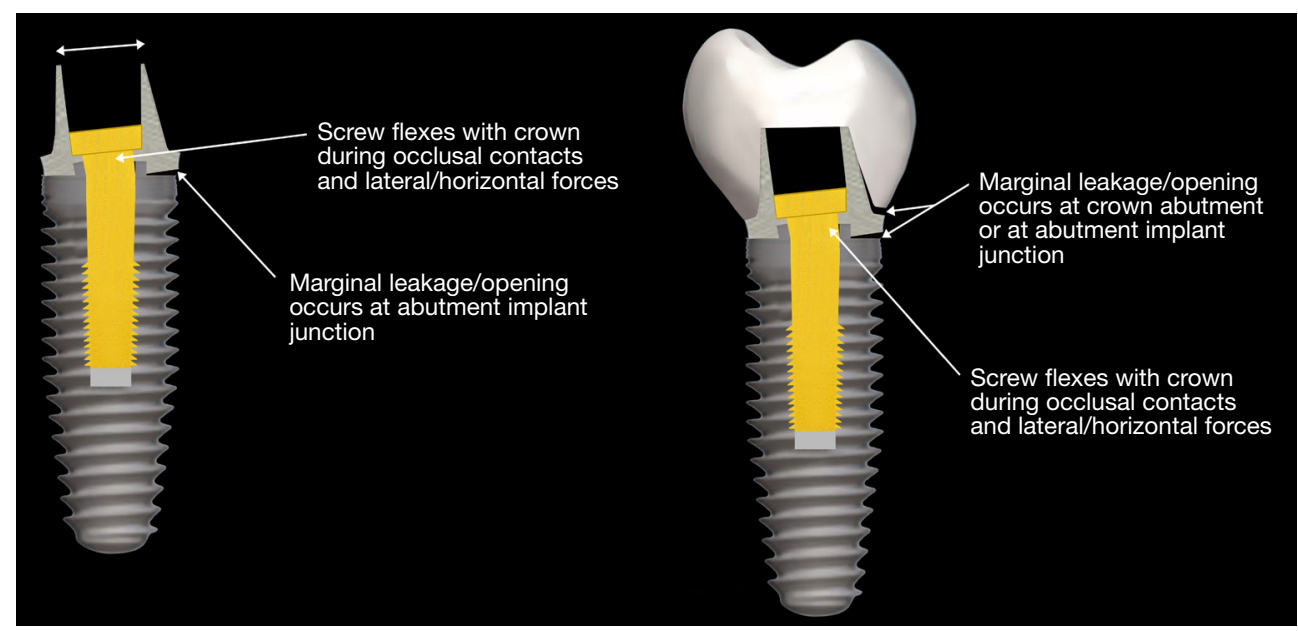

Figure 7 Lateral occlusal forces over a period of time can cause bending of the prosthetic screw illustrated in this figure. This bending will eventually cause the abutment to loosen and an opening at either the implant-abutment or abutment-crown or both interfaces to occur. This is a common reason for screw fracture in external hex dental implant system.

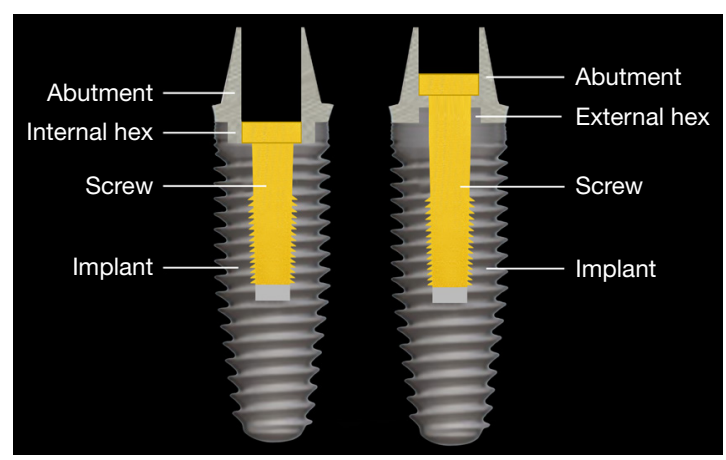

Figure 8 Cross-sections of internal and external implant systems illustrating the relationships of abutment, screw and implant.

apex. This design has two advantages. The width at the crest provides greater strength to the wall of the implant. The dimensions of the implant - width and length-influence the stresses transferred to the surrounding bone (21). However, if the load point on the crown from the opposing dentition is lateral, i.e., outside of the confines of the implant walls, there is a larger horizontal vector of stress with magnified strain (Figure 10). A sufficient thickness of the implant wall is important to prevent hoop stresses that could distort the coronal form of the implant and place stress on the bone surrounding the crestal area of the implant as illustrated in Figure 11. As such, the occlusal forces are transferred through the abutment to the crestal portion of the implant. It is this portion of the implant that receives the greatest stress from the abutment. The horizontal vector of these forces is most capable of displacing the abutment and loosening the abutment screw (22) (Figure 7). The implant base, the apex, is narrower than the crest and is ideally designed to be stabilized by the surrounding bone $(23,24)$ (Figure 11). The amount of bone surrounding the apical tip of the implant is well able to stabilize the implant from the vertical vector of occlusal forces. However, it is the length of the implant that serves to resist the rotational movements of the implant system. Nevertheless, in evaluating the stresses placed upon the body of the implant two factors must be considered. The first is that the fulcrum for rotation of the implant lies at its apex that is located in the bone. Secondly, because the interface of the abutment and the implant is made up of two fitted structures, and the fulcrum for the abutment lies at its interface with the crestal area of the implant, movement (strain) of the abutment relative to the implant is possible (25). Most of the current implant systems utilize internally fitted abutment. If the abutment moves relative to the implant, distortion of the crestal portion and perhaps of the body of the implant may occur because a portion of the abutment lies within the crestal portion of the implant. A longer implant is more effective in resisting this stress. However, a deep internal connection may reduce the effectiveness of the length of the implant to resist the torquing forces on the implant and consequently lead to the strain in the crestal bone both because of the thinness of the crestal area of the wall of the implant and secondly, the rigidity of the connection results in a longer lever arm. This observation 


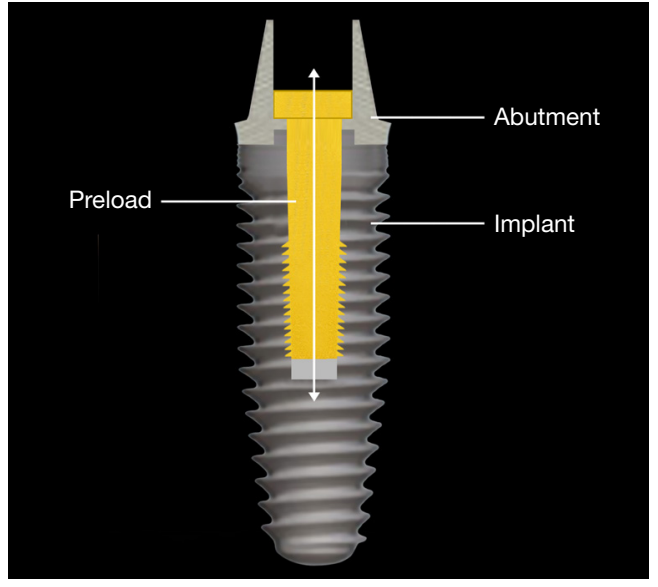

Figure 9 The prosthetic screw in the center connects the abutment and crown (upper compartment) to the dental implant (lower compartment). Once the screw is torqued to the manufacturer's recommendation, there is a certain amount of tensile force, the pre-load, which is generated. This is illustrated by the arrow in the center of the prosthetic screw. The pre-load generates a clamping force which results in tight contact between dental implant and abutment.



Figure $10 \mathrm{~A}$ broader occlusal table permits contact points that are unsupported because they are outside the diameter of the osseointegrated implant.

is supported by both experimental studies and clinical observation (26). With regard to the stress transfer from the implant to the supporting bone, a number of authors have suggested that the crestal area is the site for the greatest stress transfer $(27,28)$ (Figure 12).

\section{Bone-implant integration}

Initially implants are mechanically stabilized (primary stability) by virtue of the fact that they are designed to be slightly wider in diameter than the drills that are used to prepare the osteotomy in the bone for implant insertion. The edges of the threads engage the walls of the osteotomy to stabilize the implant. Gradually over time as the trauma of the drilling into the bone heals, bone grows into intimate contact with the oxide layer on the surface of the implant. This process called "osseointegration" has been well characterized and the reader is referred to a number of available reviews (29).

There are three phases to this process. They have been described as the inflammatory phase, the healing or repair phase, and the remodeling phase. The first two phases are strictly biologically mediated. It is in the third phase, remodeling, that the mechanics of stress and the resultant strain mediate and can modify the biological response of the osseous structure surrounding and supporting the implant (30). The stress applied to the implant system from occlusal forces are transferred, as described previously, through the crown and abutment to the abutment-implant interface and ultimately through the implant to the supporting bone. The forces, that is, the stress can result in strain which, in our case, is the deformation of the osseous structures supporting the implant (31). The applied strain elicits a response from the bone through a process called mechanotransduction (32).

\section{Bone strain}

In the 1990's an orthopedist, Frost, quantified the response of bone to strain (33). He described three zones of strain which elicited the responses from bone tissue. The first was termed as "disuse atrophy", in which the applied strain was minimal or non-existent. This occurs when the associated microstrain is at or below $200 \mathrm{~ms}$. Resorption of the skeleton occurs because there is little environmental challenge. This was similarly observed with reduced gravity in the space station orbiting the earth. Because of minimal gravitational force, astronauts who inhabited the station without exercise lost muscle mass and bone mineral. The second is microstrain in the order of 1,500 to $3,000 \mathrm{~ms}$. With applied strain of such magnitudes bone remodeling and modeling occurs. The mechanism appears to require the activation of osteocytes followed by the recruitment of osteoclasts and 


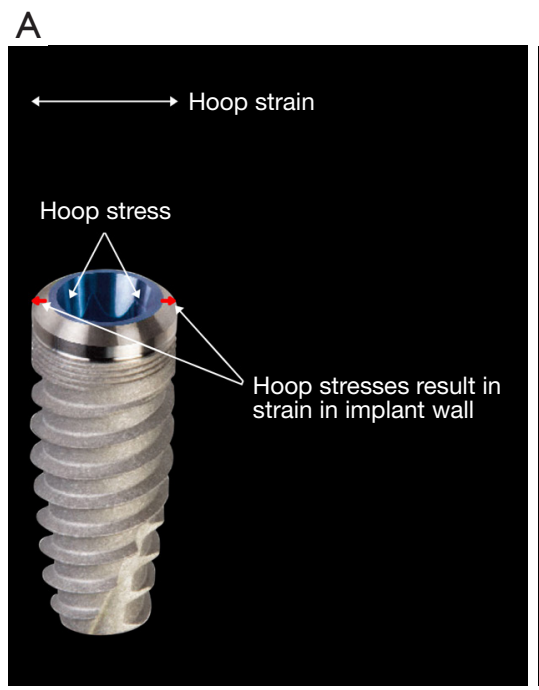

B

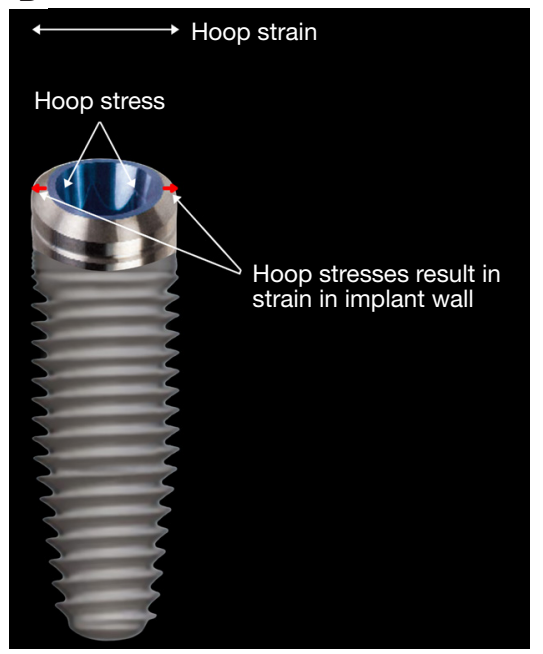

Figure 11 Shear stresses can distort the walls of the dental implant as illustrated. This phenomenon is described as hoop stress and hoop strain.

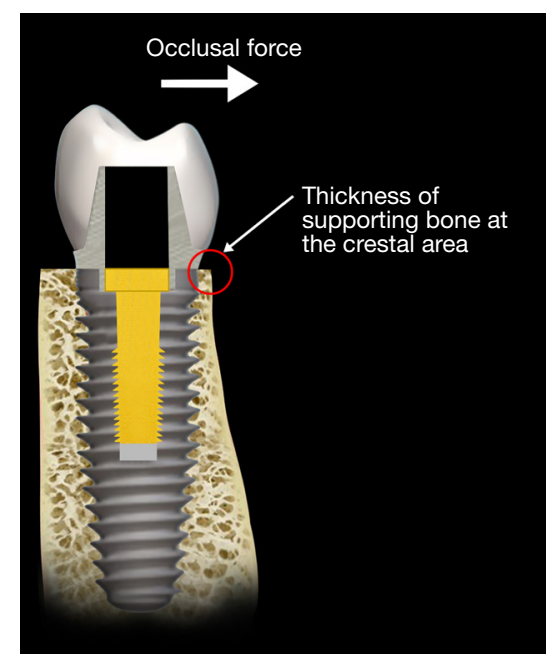

Figure 12 Crestal bone thickness is important to provide support for dental implants. A minimum of $2 \mathrm{~mm}$ of crestal bone thickness is required to maintain the crestal bone position without fatiguing microfracture and resorption.

osteoblasts. Initial formation and recruitment of osteoclasts are necessary to resorb damaged areas or weakened osteoid. This is followed by the differentiation and migration of osteoblasts with the formation of new bone (Figure 13). The newly formed bone can thicken and strengthen the bone matrix and prevent microcracks and fracture. In the third strain zone, overuse that is, in response to excessive strain, greater than 3,000 ms, the bone attempts to repair itself but because of microfracture of the bone from the excessively applied force, resorption dominates and the repair is less than complete.

Frost termed the homeostatic mechanism that responds to the mechanical environment as "a mechanostat" (34). He initially hypothesized that the homeostatic response is mainly associated with the magnitude of strain to which the bone is subjected. Further research by Skerry suggests that other factors associated with the applied strain are also important (35). These include the rate of strain application, the frequency of application and the distribution of strain within the bone. Accumulating evidence has demonstrated that the response of the mechanostat is regulated by the osteocytes that dwell within lacunae in the Haversian systems in both cortical and trabeculae structures (36). Interruptions in the interstitial fluid system that links the osteocytes to each other and their nutritional source and changes in the intercanalicular pressure gradient provide a signaling cascade that modulates the formation of osteoclasts and differentiation of preosteoblasts. This signaling process is an example of mechanotransduction (37). Strain, a macroscopic mechanic process that causes the distortion in the bone, results in the changes in the interstitial canalicular pressure between osteocytes, which subsequently modulate the cytoskeleton of the osteocytes and consequently are transformed into a biochemical signal. The biochemical signal recruits osteoclasts and osteoblasts 


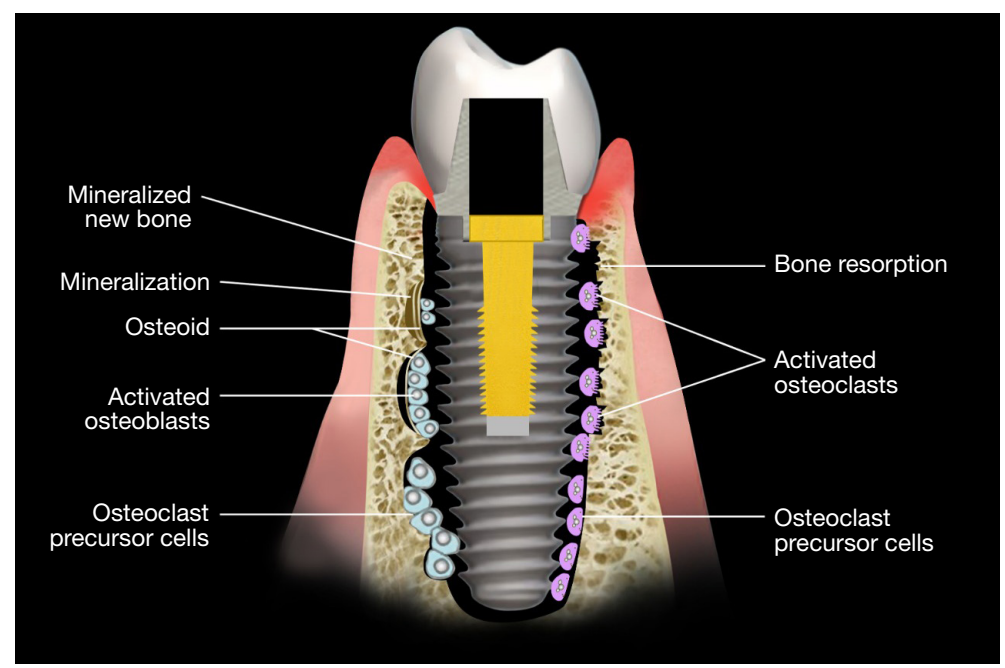

Figure 13 The bone remodeling cycle. Microscopic damage within bone is repaired by the coordinated action of osteoclasts and osteoblasts. Osteoclasts initially resorb the damaged bone. Following this osteoblasts lay down an osteoid matrix that subsequently mineralizes.

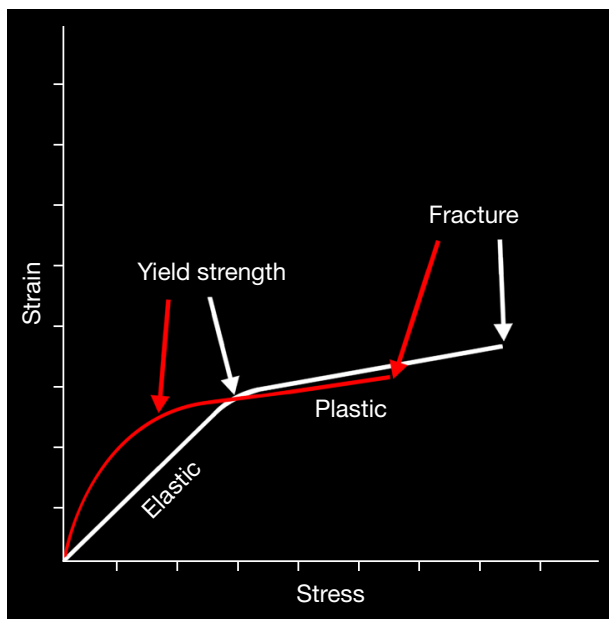

Figure 14 The effects of fatigue upon material deformation illustrated with titanium as an example. The white curve represents a typical material performance. The red curve represents the effects of cyclic loading, a form of fatigue common in the oral cavity, upon material performance. Note that with fatigue the amount of strain under a given load (stress) is greater and that the fracture of the material requires less force (stress). In creating this figure, we have followed the convention often used in the engineering literature in which the actual units of measure not necessarily included as the shape and position of the curves demonstrate the different states, which in this case is bending and fracture with and without fatigue. into the remodeling process.

\section{Dental peri-implant strains}

The strains in the peri-implant osseous structure are important considerations since the surrounding bone provides the primary stability for the implant system. Generally, strains in the mechanical structures are characterized either as elastic, plastic and yield strains $(38,39)$ (Figure 14). Elastic strains do not result in permanent deformation of the structure. As soon as the stress is relieved the structure returns to its original form. Plastic strain results in permanent deformation of the structure. The degree of change in the structure has been reported to be dependent upon the magnitude of the stress, the repetition rate of the stress, and the modulus of elasticity of the structure. Yield strains are of larger magnitude and are associated with displacement and fracture. The stresses in the oral cavity are usually below the yield point of most of the mechanical structures present. However, because the stresses are generally repetitive and cyclic in nature, the issue of fatigue and its effect on the strain transfer to structures in the oral cavity (teeth) and those installed therapeutically (restorations) can dramatically increase the strain/stress curve values $(40,41)$ (Figure 14). As a result, 
larger deformations at lower stress levels are often observed. Consequences of this situation are the development of "wear and tear" (42). Examples of this process include crown displacement, screw and abutment loosening and fracture. Less common but of greater consequence is the fracture of the implant and loosening of the implant in its osseous housing (43).

The examples of "wear and tear" cited above are mechanical. These can only be addressed through alterations, by the clinician, in the structures of the implant system. These might include altering the morphology of the crown or tightening of a screw (44). However the "wear and tear" in the osseous support can be addressed biologically, i.e., dynamically (45). The remodeling process replaces bone wearing out through fatigue and microfracture. It has been estimated that the weight bearing bones can fracture after 3 years without the remodeling process. More recent research suggests that not only the nature of the materials (modulus of elasticity) but also its internal structure is important to resist the fracture (46). In the case of dental implants the thickness and type of bone supporting the implant system are important considerations particularly the facial aspect of the osseous support for the implant (47). It is in this direction that the horizontal movement of the jaw loads the implant system through the crown (Figure 13). It further seems that the crestal bone adjacent to the superior aspect of the implant receives the greatest stress during horizontal loading since an axis of rotation of the implant system associated with the implant-abutment interface is located here (48). For the crestal bone, the thickness and characteristics of the bone (cortical $v s$. trabecular bone) are important considerations. Minimal bone width, i.e., less than $2 \mathrm{~mm}$, on the facial aspect of the implant system can readily lead to fatigue and micromovement in the lateral direction. The likelihood of micromovement of the implant, particularly if it is more than $4 \mathrm{~mm}$ wide, may result in displacement of the implant system. With this regard, the crown/implant ratio is an important parameter since a larger ratio would result in a longer lever arm, putting greater stress on the crestal bone with greater resultant strain (49).

\section{Clinical significance of peri-implant strain}

There are a number of clinical strategies that are employed to reduce the strains associated with forces that act upon oral implant systems (50). These take advantage of an understanding of the biomechanical issues raised in this review that are important considerations for successful implant treatment, some of which are cited above. A common strategy narrows the occlusal dimensions of the crown to reduce the number of occlusal contact points, particularly those that produce torquing forces on the abutment-implant interface. Several additional strategies, cited before, are oftentimes adopted. For example, flattening of the morphological characteristics of the occlusal surface of the crown (the cusp angles) can reduce the horizontal vector of occlusal force acting upon the implant system. Selecting an implant system with a deep internal connection between the implant and abutment provides greater stability to the implant-abutment joint. Increasing the diameter of the osseous bed that supports the implant system strengthens the stability of the implant in the bone. All these serve to distribute more widely the stresses associated with oral function and reduce the associated strain and thus may improve long-term stability and retention of the implant system.

\section{Concluding remarks and future outlook}

Dental implantology has made much progress since the introduction of critical scientific analyses in the 1960's. The groundbreaking work of Branemark, Strauman and Schroeder provided the foundation for understanding the biological integration of the dental implant within the jawbone (30). A number of strategies have been explored to modulate the current osseointegration process in order to achieve improved stability and predictability, while continuously seeking novel integration mechanisms.

In parallel, the biomechanics of the dental implant system, the subject of this review, are undergoing remarkable development. The adoption of $3 \mathrm{D}$ highresolution finite element analysis (FEA) allows identifying possible imperfections in the current implant system designs (51). Extension of digital technology to dental implant component manufacture enabling custom designs having better fit within the confines of the skeletal structure of the patient. Such endeavors typically involve the virtual design by combining STL and DICOM files and subsequent manufacturing either by milling or $3 \mathrm{D}$ printing technologies (52). At the same time a more fundamental understanding of the interface between the physiological processes of integration and the biomechanical activities in the oral cavity can lead to better predictability and improved stability of the implant-osseous interface (53).

Another important area that should not be overlooked are the developments in material sciences. These include the 
utilization of ceramic and hybrid materials such as Rocksolid and Trabecular metal for the implant and the development of implant surfaces that facilitate biomechanical integration. The goal is to provide greater strength while improving the predictability for the osseous interface with the implant (54). Another intriguing strategy that holds much promise is the introduction of stem cells within 3D printed hybrid structures. This opens an entirely new era in terms of interfacial compatibility between biological (native to the patient) and mechanical (manufactured in the laboratory) structures and has implications beyond the oral cavity (55). Clearly, the research and developments in implant science is part of the developing relationship between the biology of the oral cavity and systemic health that holds the promise of a bright future.

\section{Acknowledgments}

Funding: None.

\section{Footnote}

Reporting Checklist: The authors have completed the Narrative Review reporting checklist. Available at https:// fomm.amegroups.com/article/view/10.21037/fomm-21-50/ rc

Peer Review File: Available at https://fomm.amegroups.com/ article/view/10.21037/fomm-21-50/prf

Conflicts of Interest: All authors have completed the ICMJE uniform disclosure form (available at https://fomm. amegroups.com/article/view/10.21037/fomm-21-50/coif). The authors have no conflicts of interest to declare.

Ethical Statement: The authors are accountable for all aspects of the work (if applied, including full data access, integrity of the data and the accuracy of the data analysis) in ensuring that questions related to the accuracy or integrity of any part of the work are appropriately investigated and resolved.

Open Access Statement: This is an Open Access article distributed in accordance with the Creative Commons Attribution-NonCommercial-NoDerivs 4.0 International License (CC BY-NC-ND 4.0), which permits the noncommercial replication and distribution of the article with the strict proviso that no changes or edits are made and the original work is properly cited (including links to both the formal publication through the relevant DOI and the license). See: https://creativecommons.org/licenses/by-nc-nd/4.0/.

\section{References}

1. Matsuo K, Palmer JB. Anatomy and physiology of feeding and swallowing: normal and abnormal. Phys Med Rehabil Clin N Am 2008;19:691-707, vii.

2. Nilner M, Lassing SA. Prevalence of functional disturbances and diseases of the stomatognathic system in 7-14 year olds. Swed Dent J 1981;5:173-87.

3. Weinberg LA. The biomechanics of force distribution in implant-supported prostheses. Int J Oral Maxillofac Implants 1993;8:19-31.

4. Ramos Verri F, Santiago Junior JF, de Faria Almeida DA, et al. Biomechanical influence of crown-to-implant ratio on stress distribution over internal hexagon short implant: 3-D finite element analysis with statistical test. J Biomech 2015;48:138-45.

5. Buschang PH, Hayasaki H, Throckmorton GS. Quantification of human chewing-cycle kinematics. Arch Oral Biol 2000;45:461-74.

6. Eskitascioglu G, Usumez A, Sevimay M, et al. The influence of occlusal loading location on stresses transferred to implant-supported prostheses and supporting bone: A three-dimensional finite element study. J Prosthet Dent 2004;91:144-50.

7. Takahashi JM, Dayrell AC, Consani RL, et al. Stress evaluation of implant-abutment connections under different loading conditions: a 3D finite element study. J Oral Implantol 2015;41:133-7.

8. Steinebrunner L, Wolfart S, Ludwig K, et al. Implantabutment interface design affects fatigue and fracture strength of implants. Clin Oral Implants Res 2008;19:1276-84.

9. Quek HC, Tan KB, Nicholls JI. Load fatigue performance of four implant-abutment interface designs: effect of torque level and implant system. Int J Oral Maxillofac Implants 2008;23:253-62.

10. Wang RF, Kang B, Lang LA, et al. The dynamic natures of implant loading. J Prosthet Dent 2009;101:359-71.

11. Alkan I, Sertgöz A, Ekici B. Influence of occlusal forces on stress distribution in preloaded dental implant screws. J Prosthet Dent 2004;91:319-25.

12. Zipprich H, Rathe F, Pinz S, et al. Effects of Screw Configuration on the Preload Force of Implant-Abutment Screws. Int J Oral Maxillofac Implants 2018;33:e25-32. 
13. Uhl RL. The biomechanics of screws. Orthop Rev 1989;18:1302-7.

14. Özkurt Z, Kazazoğlu E. Zirconia dental implants: a literature review. J Oral Implantol 2011;37:367-76.

15. Andreiotelli M, Wenz HJ, Kohal RJ. Are ceramic implants a viable alternative to titanium implants? A systematic literature review. Clin Oral Implants Res 2009;20 Suppl 4:32-47.

16. Johansson CB, Han CH, Wennerberg A, et al. A quantitative comparison of machined commercially pure titanium and titanium-aluminum-vanadium implants in rabbit bone. Int J Oral Maxillofac Implants 1998;13:315-21.

17. Cinel S, Celik E, Sagirkaya E, et al. Experimental evaluation of stress distribution with narrow diameter implants: A finite element analysis. J Prosthet Dent 2018;119:417-25.

18. Park JH, Lim YJ, Kim MJ, et al. The effect of various thread designs on the initial stability of taper implants. J Adv Prosthodont 2009;1:19-25.

19. Abuhussein H, Pagni G, Rebaudi A, et al. The effect of thread pattern upon implant osseointegration. Clin Oral Implants Res 2010;21:129-36.

20. O'Sullivan D, Sennerby L, Jagger D, et al. A comparison of two methods of enhancing implant primary stability. Clin Implant Dent Relat Res 2004;6:48-57.

21. Raaj G, Manimaran P, Kumar CD, et al. Comparative Evaluation of Implant Designs: Influence of Diameter, Length, and Taper on Stress and Strain in the Mandibular Segment-A Three-Dimensional Finite Element Analysis. J Pharm Bioallied Sci 2019;11:S347-54.

22. Lee JH, Huh YH, Park CJ, et al. Effect of the Coronal Wall Thickness of Dental Implants on the Screw Joint Stability in the Internal Implant-Abutment Connection. Int J Oral Maxillofac Implants 2016;31:1058-65.

23. Marcián P, Wolff J, Horáčková L, et al. Micro finite element analysis of dental implants under different loading conditions. Comput Biol Med 2018;96:157-65.

24. Chun HJ, Cheong SY, Han JH, et al. Evaluation of design parameters of osseointegrated dental implants using finite element analysis. J Oral Rehabil 2002;29:565-74.

25. Cehreli M, Duyck J, De Cooman M, et al. Implant design and interface force transfer. A photoelastic and straingauge analysis. Clin Oral Implants Res 2004;15:249-57.

26. Pico A, Martín-Lancharro P, Caneiro L, et al. Influence of abutment height and implant depth position on interproximal peri-implant bone in sites with thin mucosa: A 1-year randomized clinical trial. Clin Oral Implants Res 2019;30:595-602.
27. Pommer B, Bucur L, Zauza K, et al. Meta-analysis of oral implant fracture incidence and related determinants. J Oral Implants 2014;2014:7.

28. Miyamoto I, Tsuboi Y, Wada E, et al. Influence of cortical bone thickness and implant length on implant stability at the time of surgery--clinical, prospective, biomechanical, and imaging study. Bone 2005;37:776-80.

29. Buser D, Sennerby L, De Bruyn H. Modern implant dentistry based on osseointegration: 50 years of progress, current trends and open questions. Periodontol 2000 2017;73:7-21.

30. Cooper LF. Biologic determinants of bone formation for osseointegration: clues for future clinical improvements. J Prosthet Dent 1998;80:439-49.

31. Delgado-Ruiz RA, Calvo-Guirado JL, Romanos GE. Effects of occlusal forces on the peri-implant-bone interface stability. Periodontol 2000 2019;81:179-93.

32. Szmukler-Moncler S, Salama H, Reingewirtz Y, et al. Timing of loading and effect of micromotion on bonedental implant interface: review of experimental literature. J Biomed Mater Res 1998;43:192-203.

33. Frost HM. Strain and other mechanical influences on bone strength and maintenance. Curr Opin Orthop 1997;8:60-70.

34. Frost HM. Bone's mechanostat: a 2003 update. Anat Rec A Discov Mol Cell Evol Biol 2003;275:1081-101.

35. Skerry TM. One mechanostat or many? Modifications of the site-specific response of bone to mechanical loading by nature and nurture. J Musculoskelet Neuronal Interact 2006;6:122-7.

36. Kamijou T, Nakajima T, Ozawa H. Effects of osteocytes on osteoinduction in the autogenous rib graft in the rat mandible. Bone 1994;15:629-37.

37. Hughes JM, Petit MA. Biological underpinnings of Frost's mechanostat thresholds: the important role of osteocytes. J Musculoskelet Neuronal Interact 2010;10:128-35.

38. Frost HM. From Wolff's law to the Utah paradigm: insights about bone physiology and its clinical applications. Anat Rec 2001;262:398-419.

39. Ashman RB, Van Buskirk WC. The elastic properties of a human mandible. Adv Dent Res 1987;1:64-7.

40. Martin AD, McCulloch RG. Bone dynamics: stress, strain and fracture. J Sports Sci 1987;5:155-63.

41. Aboushelib MN. Simulation of cumulative damage associated with long term cyclic loading using a multilevel strain accommodating loading protocol. Dent Mater 2013;29:252-8.

42. Schaffler MB, Radin EL, Burr DB. Mechanical and 
morphological effects of strain rate on fatigue of compact bone. Bone 1989;10:207-14.

43. Carter DR, Caler WE, Spengler DM, et al. Fatigue behavior of adult cortical bone: the influence of mean strain and strain range. Acta Orthop Scand 1981;52:481-90.

44. Maminskas J, Puisys A, Kuoppala R, et al. The Prosthetic Influence and Biomechanics on Peri-Implant Strain: a Systematic Literature Review of Finite Element Studies. J Oral Maxillofac Res 2016;7:e4.

45. Torres AM, Trikanad AA, Aubin CA, et al. Bone-inspired microarchitectures achieve enhanced fatigue life. Proc Natl Acad Sci U S A 2019;116:24457-62.

46. Lin D, Li Q, Li W, et al. Mandibular bone remodeling induced by dental implant. J Biomech 2010;43:287-93.

47. I-Chiang C, Shyh-Yuan L, Ming-Chang W, et al. Finite element modelling of implant designs and cortical bone thickness on stress distribution in maxillary type IV bone. Comput Methods Biomech Biomed Engin 2014;17:516-26.

48. Merheb J, Van Assche N, Coucke W, et al. Relationship between cortical bone thickness or computerized tomography-derived bone density values and implant stability. Clin Oral Implants Res 2010;21:612-7.

\section{doi: $10.21037 /$ fomm-21-50}

Cite this article as: Weiner S, Bashiri R, Wang $\mathrm{H}$. The role of peri-implant strains in dental implant systems: a narrative review. Front Oral Maxillofac Med 2023;5:19.
49. Rozé J, Babu S, Saffarzadeh A, et al. Correlating implant stability to bone structure. Clin Oral Implants Res 2009;20:1140-5.

50. Stanford CM, Brand RA. Toward an understanding of implant occlusion and strain adaptive bone modeling and remodeling. J Prosthet Dent 1999;81:553-61.

51. Unsal GS. Three-Dimensional Finite Element Analysis of Different Implant Configurations in Enlarged First Molar Areas. Int J Oral Maxillofac Implants 2020;35:675-83.

52. Joda T, Zarone F, Ferrari M. The complete digital workflow in fixed prosthodontics: a systematic review. BMC Oral Health 2017;17:124.

53. Rupp F, Liang L, Geis-Gerstorfer J, et al. Surface characteristics of dental implants: A review. Dent Mater 2018;34:40-57.

54. Park S, Kim H, Choi KS, et al. Graphine-Chitosan hybrid dental implants with enhanced antibacterial and cell proliferation properties. Appl Sci 2020;10;4888.

55. Lucaciu O, Soriţău O, Gheban D, et al. Dental follicle stem cells in bone regeneration on titanium implants. BMC Biotechnol 2015;15:114. 